\title{
Influência da sangria na qualidade da carne de aves (Gallus domesticus) resfriada
}

\section{Influence of bleeding in refrigerated poultry (Gallus domesticus) meat}

\author{
Sérgio Borges Mano, Henrique Silva Pardi, Mônica Queiroz de Freitas
}

\section{Resumo}

Para avaliar a influência da deficiência de sangria na qualidade dos peitos de aves (Gallus domesticus), foram analisadas 64 amostras de frangos abatidos de modo industrial. As amostras, subdivididas entre bem e mal sangradas, foram conservadas sob refrigeração $\left(4 \pm 1^{\circ} \mathrm{C}\right) \mathrm{du}$ rante sete dias. Realizaram-se análises microbiológicas (contagem total de microrganismos aeróbios, mesófilos e psicrotróficos), determinação de $\mathrm{pH}$ (método potenciométrico) e bases voláteis totais (microdifusão em placa de Conway), no $1^{\circ}$ e $7^{\circ}$ dias de conservação. De acordo com os resultados, constatou-se a eficiência dos métodos microbiológicos e físico-químicos, pois houve uma diferença estatística significativa $(P<0.01)$ entre o $1^{\circ}$ e $7^{\circ}$ dias das análises realizadas. Concluiu-se também que não houve diferença significativa $(P>0.05)$ comprovada estatisticamente (análise de variância e teste de Duncan), nas diversas análises entre as amostras de frangos bem e mal sangrados sugerindo-se o estudo do possível aproveitamento das carcaças dos mal sangradas na elaboração de produtos pós-processados de aves.

Palavras chave: Gallus domesticus; aves; sangria

\section{Introdução}

Há muito tempo a sangria dos animais destinados ao consumo humano, é preocupante; diversos pesquisadores (Tarver e May, 1963; Kuenzel et al., 1978; Warriss, 1984; Heath, 1984) procuraram estabelecer um melhor método e um melhor tempo de sangria, a fim de obter maior quantidade de sangue drenado.

Atualmente, com o crescimento da produção e do consumo de carne de frango, o sacrifício em larga escala aumentou bastante com a introdução de modernos equipamentos que realizam o processo de abate em menor tempo e com maior eficiência atendendo aos princípios higiênico-sanitários e tecnológicos. Algumas vezes essa metodologia, no caso especial da sangria, pode vir a comprometer a qualidade do produto final, ocasionando um aumento do índice de perdas (condenações totais ou parciais) como Harris e Carter (1977) observaram ao estu- darem, comparativamente, a eficiência da sangria quando realizada manual ou mecanicamente, encontrando um aumento significativo do residual de sangue nas carcaças sangradas pelo segundo método.

Pode-se definir sangria como a efusão intencional de sangue do animal, tendo como objetivo principal causar a sua morte. Podem ser citados outros propósitos advindos de uma sangria completa, como a melhoria da aparência da ave, a diminuição da quantidade de sangue na carcaça e no tanque de escaldagem e, ainda, o aproveitamento do sangue para elaboração de subprodutos (farinhas). Segundo o Regulamento da Inspeção Industrial e Sanitária de Produtos de Origem Animal - RIISPOA (Brasil, 1952), os processos de matança realizados em aves obedecem a regra geral relativa às demais espécies de açougue, isto é, obrigatoriamente proceder-se-á à sangria, sendo proibido qualquer processo que não provoque a efusão de sangue. Os métodos de matança preconizados no artigo 138 são: (1) incisão das jugulares através da boca, seguida de destruição da medula alongada, quando se pretende realizar a depenação a seco, (2) incisão das jugulares externamente, e (3) ferida de sangria de cada lado do pescoço, pela inserção de um instrumento perfurocortante nessa região. Do artigo 140, do mesmo Regulamento, consta, expressamente: "A sangria deve ser completa". O artigo 172 considera como carnes repugnantes, condenando-as, as carcaças que apresentem mau aspecto, coloração anormal ou que exalem odores medicamentosos, excrementiciais, sexuais e outros considerados anormais.

O tempo mínimo de sangria determinado pelo Ministério da Agricultura (Brasil, 1973), é de 3 min., antes dos quais não será permitida qualquer outra operação; a sangria deve ser realizada imediatamente após a insensibilização.

Kuenzel e Ingling (1977), comentam que a meta inicial do processamento de aves, a sangria, deve ser otimizada o máximo possível, pois a eficiência da sangria de cada ave irá (1) melhorar a qualidade da carcaça, (2) permitir um máximo recolhimento de sangue para reciclagem (farinhas), e (3) diminuir a quantidade de sangue difundido na água de escaldagem. 
Harris e Carter (1977) afirmam que as aves mal sangradas podem vir a ser condenadas pela inspeção norte-americana como "cadáveres", ou ser depreciadas devido ao excesso de sangue localizado no músculo ou difundido. Essa afirmação, baseia-se no Regulamento de Inspeção de Aves Norte-americano (Poultry Inspector's Handbook) (Estados Unidos da América, 1968) posteriormente ratificado pelo Compêndio de Inspeção de Aves (Poultry Inspection Compendium) (Estados Unidos da América, 1982), onde "cadáveres", são definidos como aves que morreram por outra causa que não seja o abate. Os mesmos autores ainda caracterizam as aves mal sangradas como sendo aquelas que apresentam vermeIhidão de pele, engurgitamento dos vasos sangüíneos viscerais, congestão do coração, fígado e baço, indicando como possíveis causas o inadequado corte de sangria e o tempo insuficiente entre a sangria e a escaldagem.

Kuenzel et al. (1978), trabalhando com insensibilização elétrica e tempo de sangria em aves, citam a importância da remoção do sangue, com objetivo não só de aumentar a qualidade da carcaça, como também de diminuir a quantidade de sangue no tanque de escaldagem, reduzindo, conseqüentemente, o conteúdo orgânico dos efluentes. Afirmam também que a maior parte do sangue é drenado nos primeiros 30 a $40 \mathrm{seg}$.

Grossklaus (1979) afirma que a sangria incompleta é um fator que favorece, de maneira decisiva, a putrefação. Barros e Vianni (1979) confirmam ser a sangria completa fator de maior importância tecnológica para posterior conservação da carne, sendo a degola o melhor processo de sangria, com o tempo variando de 2 a $4 \mathrm{~min}$. Relatam a ocorrência de carcaças com coloração avermelhada, dando a impressão de pele queimada, quando a sangria é imperfeita.

Heath et al. (1981) questionam o porquê da condenação de aves mal sangradas, contestando Chambers (1979) que afirma existir uma melhoria da qualidade da carcaça do frango quanto maior for a remoção de sangue, porém, sem citar evidências para esta afirmação.

Bald (1988) pesquisou o aproveitamento da carne de aves mal sangradas (peito e coxa), adicionando $50 \%$ destas carnes na fabricação de embutidos cozidos (mortadela de frango e salsicha). Realizou análises ( $\mathrm{pH}$, contagem total, contagem de coliformes e Staphylococcus aureus) comparativas das carcaças de aves bem e mal sangradas, após $24 \mathrm{~h}$, realizando também as análises nas salsichas e mortadelas de frango, com 9 e 15 dias, respectivamente. Concluiu que, não houve alteração significativa entre as análises e que os produtos testados estavam dentro dos padrões sanitários.

Em muitos países são consumidos e transportados para o mercado internacional, grandes quantidades de carnes de aves e produtos derivados. Os processadores e os governos dos países consumidores e importadores demonstram grande interesse na microbiota bacteriana desses produtos como indicadora de sanidade, armazenamento, vida útil do produto e risco para a saúde pública. Portanto, à medida que as bactérias se multiplicam, o pH se eleva e aumenta a quantidade de amoníaco e compostos afins (ainda que essas mudanças não sejam marcadas e mesmo que o nível de bactérias psicrófilas exceda a $\left.10^{6}\right)$. As principais causadoras de alterações são as Pseudomonas: P. fluorenciens, $P$. putida, $P$. fragi e as espécies afins, e em menor grau as Alteromonas putrefaciens. A International Commission Microbiological Specification for Food (ICMSF, 1980), conclui que o cultivo de aeróbios em placas incubadas a $35^{\circ} \mathrm{C}$, temperatura em que podem crescer os organismos mesófilos, pode servir de indicador de higiene global das carnes de aves, e que 0 cultivo de aeróbios em placas incubadas a $17-35^{\circ} \mathrm{C}$, temperatura em que crescem tanto psicrófilos quanto mesófilos (inclusive incubadas a $0-5^{\circ} \mathrm{C}$ para que cresçam os psicrófilos e não os mesófilos), podem indicar o grau de alteração e a expectativa da vida útil da carcaça. Portanto, esses cultivos são valiosos para determinar o grau de contaminação microbiológica em uma operação de processamento de aves de consumo.

Mano et al. (1992), trabalhando com 36 amostras de peito de frango, procuraram determinar a importância dos métodos físico-químicos ( $\mathrm{pH}$, bases voláteis totais - BVT e filtração) em comparação com as contagens microbiológicas (aeróbios mesófilos - CTAM - e psicrotróficos - CTP) em um período de sete dias de conservação das amostras sob refrigeração $\left(4 \pm 1^{\circ} \mathrm{C}\right)$. Os resultados médios obtidos no $1^{\circ}$ e $7^{\circ}$ dias, respectivamente,

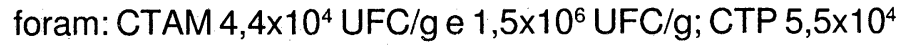

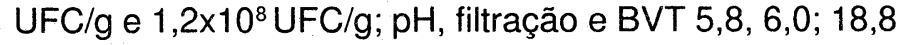
$\mathrm{ml}, 17,7 \mathrm{ml}$; e $11,76 \mathrm{mg} / 100 \mathrm{~g}, 12,45 \mathrm{mg} / 100 \mathrm{~g}$. Após as análises estatísticas, concluíram que como as variações das determinações físico-químicas são muito pequenas para, sozinhas, permitirem avaliar o estado de conservação da carne de aves, deve haver, sempre que possível um acompanhamento microbiológico, o qual se mostrou bastante eficiente.

Em relação ao pH, de acordo com Hofmann (1988), existem basicamente dois métodos diferentes de medição: os indicadores de cor e os eletrodos de vidro acoplados a um paquímetro indicador. Como o primeiro método é limitado em sua exatidão, utiliza-se a determinação eletrométrica quando é necessária uma maior precisão. $\mathrm{O}$ mesmo autor afirma que o valor do $\mathrm{pH}$ tem influência sobre a qualidade da carne, sobre a cor, a maciez, o sabor, a capacidade de retenção de água e sobre sua conservabilidade. Assim o pH influi, de maneira importante, no aspecto sensorial, na transformação do músculo em carne, bem como nos produtos cárneos, fundamentandose a medição do $\mathrm{pH}$, mediante um eletrodo de vidro, no registro de uma tensão elétrica (um "potencial"), que se origina entre um eletrodo de medição e um de referência; esse potencial é determinado pelo inverso da concentração de ions de hidrogênio da solução em que se encontram os eletrodos. 
A putrefação dos alimentos de origem animal consiste, sobretudo, em uma degradação de sua matéria protéica. A degradação protéica (destruição da estrutura primária das proteínas), é provocada inicialmente por enzimas autolíticas e microbianas, ou por hidrólise química, consistindo no desdobramento gradativo da molécula protéica até ácidos aminados, que sofrem ulterior degradação, fornecendo, por descarboxilação, aminas e $\mathrm{CO}_{2}$, e por desaminação ácidos orgânicos, ácidos não saturados, álcool etílico e $\mathrm{NH}_{3}$. As aminas que se formam são transformadas em aldeídos e estes, mais tarde, nos respectivos ácidos. A deterioração de origem microbiana provoca alterações bioquímicas importantes na carne e no suco da mesma, o qual contém ácidos aminados livres, nucleotídeos e oligopeptídeos. Estes compostos servem de nutriente para os microrganismos e são responsáveis pelo rápido crescimento dos mesmos. Na verificação do estado de conservação de carnes é utilizada a determinação de certos produtos da degradação protéica, tais como BVT (aminas e $\mathrm{NH}_{3}$ ), substâncias voláteis redutoras (ácido acético, propiônico e butírico), e os radicais finais da degradação $\left(\mathrm{H}_{2} \mathrm{~S}\right.$, indol, metilmercaptans etc.) (Laszlo et al. 1986).

Este estudo, portanto, objetivou avaliar a diferença entre as aves bem e mal sangradas, ao nível microbiológico e físico-químico, fornecendo subsídios para um aproveitamento mais racional das aves atualmente condenadas por deficiência de sangria.

\section{Material e Métodos}

Colheita das amostras - Utilizaram-se 64 peitos de frango (Gallus domesticus) com osso, pesando aproximadamente $500 \mathrm{~g}$, conservados em geladeira $\left(4 \pm 1^{\circ} \mathrm{C}\right)$ e acondicionados, individualmente, em recipientes plásticos esterilizados.

Procedeu-se a divisão em dois grupos de 32 amostras cada, com os seguintes tratamentos: (1) amostras de aves insensibilizadas com 100 volts e 0,2 amperes, sangradas durante $4 \mathrm{~h} 30 \mathrm{~min}$. através de secção bilateral dos grandes vasos do pescoço (jugular e carótida) e (2) amostras de aves insensibilizadas igualmente, porém, sem o corte dos grandes vasos (constatado ao final do processamento), caracterizando uma deficiência de sangria.

Decorrido o tempo de sangria, os dois grupos de aves foram processados de acordo com a tecnologia prevista no matadouro frigorífico: escaldamento por imersão a 59ำ (aproximadamente $3 \mathrm{~min}$.), depenagem, escaldagem dos pés e retirada da cutícula. Após o banho, as aves eram colocadas na calha de evisceração, onde eram evisceradas, lavadas e retirados os pés, pescoço e cabeça, imersas, em seguida, no spinchiller, onde ficavam por um tempo aproximado de $30 \mathrm{~min}$., saindo com uma temperatura em torno de $5^{\circ} \mathrm{C}$. Após um gotejamento de 10 min., foi feito o corte do peito que foi acondicionado em recipiente plástico, e este, em caixa isotérmica com gelo, para envio ao Laboratório de Tecnologia de Aves e Derivados da Faculdade de Veterinária da Universidade Federal Fluminense, Niterói, Estado do Rio de Janeiro, onde realizaram-se os exames microbiológicos e físico-químicos.

Os pescoços foram retirados da calha de evisceração para a comprovação, ou não, da secção dos grandes vasos, sendo separadas como mal sangrados as aves que não tivessem as jugulares e carótidas seccionadas, e como bem sangradas aquelas com secção total desses vasos.

Observou-se, também, ao final do pré-resfriamento em spinchiller, a coloração geral das aves, e foram separadas as aves bem e mal sangradas.

Métodos - As amostras em temperatura controlada de $4 \pm 1^{\circ} \mathrm{C}$, foram processadas no $1^{\circ}$ e $7^{\circ}$ dias após o abate, realizando-se análises microbiológicas (CTAM e CTP) e físico-químicos (pH e BVT). No $1^{\circ}$ dia, utilizou-se o lado direito do músculo peitoral, colhendo-se, assepticamente, alíquotas para as determinações que foram repetidas no $7^{\circ}$ dia de refrigeração com o lado esquerdo da amostra.

Para as análises microbiológicas utilizou-se uma alíquota de $10 \mathrm{~g}$ do músculo peitoral sem pele, colhida em uma área de aproximadamente $2,5 \mathrm{~cm}^{2}$, homogeneizada com $90 \mathrm{ml}$ de solução salina peptonada e separada em diluições decimais. Realizou-se semeadura em profundidade (pour plate), em duplicata, em meio ágar padrão para contagem de microrganismos (art Merk, 5463), incubando-se por $48 \pm 3 \mathrm{~h}$ em temperatura de $35 \pm 1^{\circ} \mathrm{C}$ para mesófilos, e, $10 \pm 1$ dias a $7 \pm 1^{\circ} \mathrm{C}$ para psicrotróficos (Gilliland et al., 1984). Foram feitas as contagens de acordo com o Laboratório Nacional de Referência Animal LANARA (Brasil, 1981), ou seja, em placas cujo número de unidades formadoras de colônias (UFC), encontravase entre 30 e 300 .

$\mathrm{Na}$ avaliação do $\mathrm{pH}$, utilizou-se o método potenciométrico de inserção, através do $\mathrm{PH}$-metro portátil Micro Nal mod B 278, transistorizado com alimentação por bateria de 9 volts, escala com amplitude de 0 a 14, com precisão de 0,1 unidade, e eletrodo de vidro combinado INGOLD.

Realizou-se a medição diretamente na musculatura peitoral, livre de gordura e tecido conjuntivo, a uma distância média de $2 \mathrm{~cm}$ da quilha do peito e a uma profundidade, aproximada, de $2 ; 5 \mathrm{~cm}$. As medições, mínimo de três, foram feitas em pontos diferentes, utilizando-se o valor médio observado, mantendo-se o eletrodo limpo após cada medição, e calibrado em intervalos regulares, conforme indicação do manual de instrução (Metrohm AG 9100 DIGIMED, sem data).

Para a determinação das BVTs, obedeceu-se à técnica de microdifusão em placa de Conway (Brasil, 1981).

Para o estudo da umidade das amostras, foi usado o método de estufa a $105^{\circ} \mathrm{C}$ (Brasil, 1981) no $1^{\circ}$ e $7^{\circ}$ dias de conservação. Apesar dos resultados obtidos em 20 amostras ( 10 bem sangradas e 10 mal sangradas) apresenta- 
rem uma diferença estatística (Análise de Variância e Teste "t") significativo ao nível de $1 \%(P<0,01)$, essa diferença não foi suficiente para influenciar nos resultados obtidos em mg de BVT/100g, adotando-se, portanto, a umidade média de $75,30 \%$ para a determinação das BVTs.

Análise estatística - A análise estatística constou de um delineamento inteiramente casualizado, com estudo da análise de variância entre os tratamentos (sangrado e mal sangrado), dia de análise ( $1^{\circ}$ e $7^{\circ}$ dias), seguido do estudo da diferença de médias (Teste de Duncan) e posterior estudo das correlações (correlação simples de Pearson). Usou-se para os cálculos o software SAEG (Sistema para Análises Estatísticas e Genéticas), desenvolvido por Euclides (1983), processado em microcomputador IBM-PC/XT.

\section{Resultados}

Os resultados médios (contagens microbiológicas, $\mathrm{pH}$ e BVT) bem como o desvio padrão das aves bem e mal sangradas podem ser vistos na Tabela.

A análise de variância dos resultados (CTAM, CTP, $\mathrm{pH}$ e BVT), mostrou-se significativa $(P<0.01)$ entre os dias $1^{\circ}$ e $7^{\circ}$ das análises, tanto das aves bem sangradas como das mal sangradas. Com relação ao tratamento (sangrada e mal sangrada), os resultados estatísticos das análises (CTAM, CTP, pH e BVT) não se mostraram significativos $(P>0.05)$.

As comparações das médias (CTAM, CTP, pH e BVT) realizadas através do teste de Duncan, mostraram uma diferença significativa $(P<0.01)$ entre os dias das análises não havendo diferença $(P>0.05)$ entre os tratamentos.

Os resultados de $\mathrm{pH}$ e BVT das aves bem e mal sangradas, mostraram uma tendência de correlação positiva entre o $1^{\circ}$ e $7^{\circ}$ dias de análise, bem como CTAM e CTP no $1^{\circ}$ dia e CTAM e CTP no $7^{\circ}$ dia. As aves mal sangradas, ainda apresentaram uma tendência de correlação positiva entre as CTAM no $1^{\circ}$ dia e CTP e CTAM no $7^{\circ}$ dia.

Apesar de não fazer parte das análises estatísticas, observou-se a coloração de pele e musculatura das aves bem e mal sangradas, em amostras distintas das do ex- perimento, encontrando-se uma diferença apreciável na coloração da pele e não na musculatura.

\section{Discussão e Conclusões}

De acordo com os resultados obtidos, constata-se haver discordância do artigo 140 do RIISPOA (Brasil, 1952) quando estabelece que a sangria "deve ser completa", sem no entanto definir com clareza, o que se entenderia por sangria completa. Esse mesmo Regulamento, no artigo 172, determina a condenação das carnes julgadas repugnantes, condições em que se enquadrariam as carcaças íntegras em causa, por apresentarem a pele avermelhada, destoando daquelas consideradas "normais". Em nosso experimento envolvendo análises microbiológicas (CTAM e CTP) e físico-químicas ( $\mathrm{pH}$ e BVT) de carcaças que apresentavam esta alteração (vermelhidão) não encontramos diferenças significativas entre a carne de peito de frangos considerados normais daqueles ditos "alterados". Observamos também que, apenas a pele se mostrava avermelhada, não havendo diferença digna de registro na coloração da musculatura ao final do processamento, o que nos leva a discordar de Leal (1966) e Thornton (1969) que afirmam que a sangria melhora consideravelmente a aparência e brancura da carne.

Os nossos resultados discordam dos de Tarver e May (1963), provavelmente por seu trabalho ter sido realizado em pulmões de aves com diferentes tempos de sangria, mostrando maior contaminação, à medida que decrescia o tempo de sangria. Entretanto, devemos lembrar que, atualmente, os pulmões são retirados por sucção na linha de evisceração, reduzindo essa provável contaminação por inspiração de água do tanque de escaldagem nas aves mal sangradas, por elas manterem atos reflexos quando de sua entrada no referido tanque.

Com relação ao fato de a sangria influir negativamente no tempo de conservação das aves, os nossos resultados discordam dos de Leal (1966), Thornton (1969), Grossklaus (1979), Barros e Vianni (1979) e Brown et al. (1981), pois o comportamento das aves mal sangradas,

Tabela - Média e desvio padrão das contagens totais de aeróbios mesófilos (CTAM) e psicrotróficos (CTP), pH e bases voláteis totais (BVT), no $1^{\circ}$ e $7^{\circ}$ dias de conservação das aves bem e mal sangradas

\begin{tabular}{|c|c|c|c|c|c|c|c|c|c|}
\hline \multirow{2}{*}{\multicolumn{2}{|c|}{ Amostras }} & \multicolumn{2}{|c|}{ CTAM(UFC/g) } & \multicolumn{2}{|c|}{ CTP(UFC/g) } & \multicolumn{2}{|c|}{$\mathrm{pH}$} & \multicolumn{2}{|c|}{$\mathrm{mg} \mathrm{BVT} / 100 \mathrm{~g}$} \\
\hline & & $1^{\circ} \mathrm{dia}$ & $7^{\circ} \mathrm{dia}$ & $1^{0} \mathrm{dia}$ & $7^{\circ} \mathrm{dia}$ & $1^{0} \mathrm{dia}$ & $7^{\circ}$ dia & $1^{\circ} \mathrm{dia}$ & $7^{\circ}$ dia \\
\hline $\begin{array}{l}\text { Bem } \\
\text { sangradas }\end{array}$ & $\begin{array}{l}\text { Média } \\
\mathrm{s}\end{array}$ & $\begin{array}{l}8.0 \times 10^{2} \\
1.3 \times 10^{3}\end{array}$ & $\begin{array}{l}1.0 \times 10^{5} \\
4.9 \times 10^{5}\end{array}$ & $\begin{array}{l}9.1 \times 10^{1} \\
2.8 \times 10^{2}\end{array}$ & $\begin{array}{l}5.4 \times 10^{5} \\
1.8 \times 10^{6}\end{array}$ & $\begin{array}{l}5.7 \\
0.2\end{array}$ & $\begin{array}{l}5.9 \\
0.1\end{array}$ & $\begin{array}{c}12.08 \\
0.61\end{array}$ & $\begin{array}{r}12.59 \\
0.55\end{array}$ \\
\hline $\begin{array}{l}\text { Mal } \\
\text { sangradas }\end{array}$ & $\begin{array}{l}\text { Média } \\
\mathrm{s}\end{array}$ & $\begin{array}{l}8.5 \times 10^{2} \\
1.3 \times 10^{3}\end{array}$ & $\begin{array}{l}1.1 \times 10^{5} \\
2.4 \times 10^{5}\end{array}$ & $\begin{array}{l}1.5 \times 10^{2} \\
5.5 \times 10^{2}\end{array}$ & $\begin{array}{l}2.3 \times 10^{6} \\
5.9 \times 10^{6}\end{array}$ & $\begin{array}{l}5.8 \\
0.1\end{array}$ & $\begin{array}{l}5.9 \\
0.1\end{array}$ & $\begin{array}{c}12.39 \\
0.71\end{array}$ & $\begin{array}{r}12.94 \\
0.67\end{array}$ \\
\hline
\end{tabular}

s: desvio padrão

UFC: unidade formadora de colônia 
não diferiu significativamente daquelas comprovadamente bem sangradas.

Embora não fosse objeto desse estudo, houve a constatação de vermelhidão apenas na pele das aves mal sangradas, o que está de acordo com Harris e Carter (1977), Kuenzel e Ingling (1977), Kuenzel et al. (1978), Barros e Vianni (1979) e Chambers (1979), que afirmam que a sangria completa é responsável pela melhoria da qualidade da carcaça, impede o aparecimento de carcaças com coloração avermelhada, diminui a quantidade de sangue na água de escaldagem e permite um máximo recolhimento de sangue para seu aproveitamento como matéria-prima na fabricação de farinha.

Harris e Carter (1977), Warriss (1984) e Heath (1984) concordam que, em aves mal sangradas, a maior parte do sangue se mantém retido nos vasos sangüíneos viscerais como coração, fígado e baço. Warriss (1984) e Heath (1984) afirmam que a má sangria não afeta a qualidade microbiológica do alimento, concordando com os resultados obtidos neste experimento. Ratificando estes resultados, Bald (1988) também não encontrou diferenças na qualidade microbiológica de produtos pós-processados de aves com percentuais de carne provenientes de animais mal sangrados, discordando, assim, de Brown et al. (1981).

Os resultados físico-químicos e microbiológicos encontrados, estão de acordo com o ICMSF (1980), que afirma que o $\mathrm{pH}$ se eleva em função da quantidade de amonía$c o$, aumentando também as contagens bacterianas.

Os achados apresentados também se assemelham aos encontrados por Gilliland et al. (1984), que exaltam a importância da realização da enumeração de microrganismos psicrotróficos em alimentos que são conservados a temperatura de refrigeração $\left(0-10^{\circ} \mathrm{C}\right)$, estabelecendo um valor médio de $10^{7}$ a $10^{8} \mathrm{UFC} / \mathrm{cm}^{2}$ como limite do tempo de conservação. Esses valores são superiores ao encontrado no presente trabalho $\left(10^{6} \mathrm{UFC} / \mathrm{g}\right)$.

$\mathrm{Em}$ relação às contagens microbianas, Mano et al. (1992) obtiveram resultados semelhantes tanto no $1^{\circ} \mathrm{como}$ no $7^{\circ}$ dias de análise, mostrando em seu trabalho apenas uma contagem microbiana (CTAM e CTP) ligeiramente maior, provavelmente em função da colheita da amostra ter sido realizada em abatedouros comerciais, onde nem sempre a higiene é favorável à conservação.

Os valores de $\mathrm{pH}$ e BVTs encontrados por nós nas amostras de aves bem e mal sangradas, se assemelham aos resultados de Mano et al. (1991), concordam com os de Laszlo et al. (1986) quando afirmam que a produção de aminas e $\mathrm{NH}_{3}$, faz com que $\mathrm{o} \mathrm{pH}$ aumente gradativamente e discordam dos de Brown et al. (1981), que afirmam ser o $\mathrm{pH}$ de aves mal sangradas maior que 0 de aves normais, afetando assim, adversamente, a vida de prateleira do produto e a maciez da musculatura.

De acordo com os resultados obtidos neste trabalho, pode-se concluir que, dentre as análises realizadas, as
CTAM e CTP foram as que melhor expressaram a condição de conservabilidade, porém, por ser mais factível na prática, seria aconselhável a análise preliminar das características físico-químicas, em especial o pH e as BVTs. Estas valeriam como elementos de suspeição ou indiciários uma vez que, também, se revelaram confiáveis ao apresentarem correlações estatísticas positivas significativas. Pode-se concluir que os cortes (peito) de aves mal sangradas, mantiveram comportamento semelhante (microbiológico e físico-químico), no período de sete dias de conservação sob refrigeração $\left(4 \pm 1^{\circ} \mathrm{C}\right)$, ao de aves bem sangradas. Sugere-se, de acordo com as conclusões acima, e com apoio na literatura, que novos estudos sejam realizados, no sentido do aproveitamento condicional das carcaças de aves mal sangradas na elaboração de produtos pós-processados.

\section{Agradecimentos}

À Direção do Matadouro Frigorífico COMAVE de Bom Jardim, RJ na pessoa do Sr. Paulo Erthal, pela cessão das amostras e a Dra Cláudia Emília Teixeira, pela colaboração na coIheita das amostras e incentivo ao trabalho. Ao Conselho Nacional de Desenvolvimento Científico e Tecnológico pelo apoio financeiro.

\section{Abstract \\ Influence of bleeding in refrigerated poultry (Gallus domesticus) meat}

To evaluate the influence of bad bleeding, 64 samples of breast muscle broilers (Gallus domesticus) slaughtered in industrial plants were analyzed. The samples were separated into two groups: the broilers that had good bleeding, and another group that suffered a bad bleeding. The samples were taken under refrigerated conditions $\left(4 \pm 1^{\circ} \mathrm{C}\right)$ during seven days. Microbiological analysis (plate count of mesophylic microorganism and psychrotrophyic), determination of $\mathrm{pH}$ (potenciometric method) and total volatile nitrogen (microdifusion in Conway plate) were taken on 1st and 7th days of conservation. Results showed an statistic difference $(P<0.01)$ between the 1 st and 7 th days of analysis. It was concluded that breast cut of carcasses of good and bad bleeding broilers did not show any statistic difference $(P>0.05)$. Therefore it was suggested that other researches be developed to permit that bad bleeding carcasses can be utilized in processed poultry products.

Key words: Gallus domesticus; poultry; bleed

\section{Referências bibliográficas}

BALD, P. A. Informação S.I.F. 1661 nr. 002/88, Lajeado, RS, 26 de setembro de 1988. Trabalho interno, não publicado, da Indústria Minuano - Companhia Minuano de Alimentos. BARROS, G. C. de, VIANNI, M. da C. E. Tecnologia aplicada 
às carnes bovina, suína e de aves, da produção ao consumo. Rio de Janeiro, UFRRJ, 1979. $137 \mathrm{p}$.

BRASIL. Ministério da Agricultura. Departamento Nacional de Inspeção de Produtos de Origem Animal. Regulamento da Inspeção Industrial e Sanitária de Produtos de Origem Animal - RIISPOA. Aprovado pelo decreto no 30691 de 29.03.52, alterado pelo decreto $\mathrm{n}^{\circ} \mathbf{1 2 5 5}$ de 25.06.62. Rio de Janeiro, 1952.

BRASIL. Ministério da Agricultura. DNPA. DIPOA. Inspeção de carnes: Il Aves. Circular no 373/BR. Brasília. Dez. 1973. 36p.

BRASIL. Ministério da Agricultura. Secretaria Nacional de Defesa Agropecuária. Laboratório Nacional de Referência Animal (LANARA). Métodos Analíticos Oficiais para Controle de Produtos de Origem Animal e seus Ingredientes. II. Métodos Físico Químicos. Aprovado pela Portaria nº 001 de 07/10/81. Brasília, 1981.123p.

BROWN, R. H., NUTTALL, J. E., SMITH, D. J. Poultry slaughter. Vet. Record, v. 108, n. 8, p. 171-172, 1981.

CHAMBERS, P. G. Animal regulation studies, 2. Amsterdam. Elseveier Scientific Publishing Company. 1979. 59p.

DIGIMED. Medidores de pH eletrônicos - Manual de instrução. Local: Indústria Eletrônica Ltda, sem data.

ESTADOS UNIDOS DA AMERICA. United States Department of Agriculture. Poultry Inspector's Handbook v. 81, n. 88, p. 55. 1968.

ESTADOS UNIDOS DA AMERICA. United States Department of Agriculture. Poultry Inspection Compendium. Food Safety and Inspection Service. Meat and Poultry Inspection, Washington, D. C. 1982.

EUCLIDES, R. F. Manual de Utilização do Programa SAEG (Sistema para Análises Estatísticas e Genéticas). Universidade de Viçosa, Viçosa, 1983. 59p.

GILLILAND, S. E., MICHENER, H. D., KRAFT, A. A. Psychrotrophic Microorganisms. In: American Public Health Association (APHA), Washington, D.C. Compendium of methods for the microbiological examination of foods. SPECK, M.L. Chapter 9, p.135-141, 1984.

GROSSKLAUS, D. Inspeccion sanitaria de la carne de ave. (Grossklaus, Geflugelfleischhygiene) Trad. José Romero de Arenillas. Acríbia, Zaragoza. 1979. 246 p.
HARRIS, C. E., CARTER, T. A. Broiler blood losses with manual and mechanical killers. Poultry Science, v. 56, p.18271831, 1977.

HEATH, G. B.S.The slaughter of broiler chickens. World's Poultry Science J., v. 40, n. 2, p. 151-159, 1984.

HEATH, G. B.S., WATT, D.J., WAITE, P.R., ORMOND, J.M. Poultry slaughter. Vet. Record, v. 108, n. 13, p. 288-289, 1981.

HOFMANN, K. El pH: una característica da calidad de la carne. Fleischwirtsch - espanhol, n. 1, p. 13-18, 1988.

ICMSF - INTERNATIONAL COMMISSION MICROBIOLOGICAL SPECIFICATION FOR FOOD. Ecologia Microbiana de los Alimentos, v. 2. Zaragoza, Acribia, 1980.

KUENZEL, W. J., INGLING, A.L. A comparison of plate and brine stunners, A.C. and D.C. circuits for maximizing bleed-out in processed poultry. Poultry Science, v. 56, p. 2087-2090, 1977.

KUENZEL, W. J., INGLING, A.L., DENBOW, D.M., WALTHER, J.H., SCHAEFER, M.M. Variable frequency stunning and a comparison of two bleed-out time intervals for maximizing blood release in processed poultry. Poultry Science, v. 57, n. 2, p. 449-454, 1978.

LASZLO, H., BASSO, L., COELHO, M. C. Química de Alimentos e Alterações dos Componentes Orgânicos. São Paulo: Nobel, 1986. 98 p. Cap.2: Protídeos, p. 32-43.

LEAL, L. O. P. Processamento industrial de frangos de corte. Rio de Janeiro, GB. 1966. 180p.

MANO, S. B., PARDI, H. S., QUEIROZ, M. F., SARDINHA, A. C. C. Avaliação comparativa de métodos físico-químicos utilizados no exame de carne de aves (Gallus domesticus) resfriadas. Higiene Alimentar, v. 6, n. 24, p. 18-20, 1992.

TARVER, F. R., MAY, K. N. The effect of blood time prior to scald and refrigerated storage upon bacterial counts in the auxillary diverticula of the interclavicular air sac chickens. Food Technol., v. 17, n. 2, p. 80, 1963.

THORNTON, H. Compêndio de inspeção de carnes. (Textbook of meat inspection) Trad. Aureo Lino da Silva. 5 ed. Londres, Bailliere. 1969.

WARRISS, P. D. Exsanguination of animals at slaughter and the residual blood content of meat. Vet. Record, v. 115, p. 292-295, 1984. 